\title{
Characterization of the PAS domain in the sensor-kinase BvgS: mechanical role in signal transmission
}

\author{
Elian Dupré 1,2,3,4, Alexandre Wohlkonig ${ }^{5}$, Julien Herrou 1,2,3,4,6, Camille Locht ${ }^{1,2,3,4}$, \\ Françoise Jacob-Dubuisson $n^{1,2,3,4^{*}}$ and Rudy Antoine $e^{1,2,3,4^{*}}$
}

\begin{abstract}
Background: In bacteria, signal-transduction two-component systems are major players for adaptation to environmental stimuli. The perception of a chemical or physical signal by a sensor-kinase triggers its autophosphorylation. The phosphoryl group is then transferred to the cognate response regulator, which mediates the appropriate adaptive response. Virulence of the whooping cough agent Bordetella pertussis is controlled by the two-component system BvgAS. Atypically, the sensor-kinase BvgS is active without specific stimuli at $37^{\circ} \mathrm{C}$ in laboratory conditions and is inactivated by the addition of negative chemical modulators. The structure of BvgS is complex, with two tandem periplasmic Venus flytrap domains and a cytoplasmic PAS domain that precedes the kinase domain, which is followed by additional phosphotransfer domains. PAS domains are small, ubiquitous sensing or regulatory domains. The function of the PAS domain in BvgS remains unknown.

Results: We showed that recombinant BvgS PAS proteins form dimers that are stabilized by a helical regions flanking the PAS core. A structural model of the PAS domain dimer was built and probed by site-directed mutagenesis and by biochemical and functional analyses. Although we found no ligands for the PAS domain cavity, its integrity is required for signaling. We also showed that the structural stability of the PAS core and its proper coupling to its flanking $\mathrm{N}$ - and C-terminal a helices are crucial for BvgS activity.

Conclusions: We propose that a major function of the BvgS PAS domain is to maintain conformational signals arising from mechanical strain generated by the periplasmic domain. The tight structure of the PAS core and its connections with the upstream and downstream helices ensure signaling to the kinase domain, which determines BvgS activity. Many mild substitutions that map to the PAS domain keep BvgS active but make it unresponsive to negative modulators, supporting that modulation increases conformational strain in the protein.
\end{abstract}

Keywords: Two-component system, Bordetella, Virulence regulation, PAS domain, Signaling

\section{Background}

Two-component systems (TCS) are one of the predominant signal transduction systems in bacteria, which are often essential to enable microorganisms to adapt to changes of their environment [1]. They regulate important developmental programs as well as bacterial virulence in response to environmental stimuli. Typically, they are composed of a transmembrane sensor-kinase protein and

\footnotetext{
* Correspondence: francoise.jacob@ibl.fr; rudy.antoine@pasteur-lille.fr ${ }^{1}$ Institut Pasteur de Lille, Center for Infection and Immunity, Lille, France ${ }^{2}$ CNRS UMR8204, Lille, France

Full list of author information is available at the end of the article
}

a cytoplasmic response regulator. Perception of a chemical or physical signal by the sensor leads to autophosphorylation, and then transfer of the phosphoryl group to the response regulator [2]. Thus activated, the latter mediates a specific, frequently transcriptional, cellular response.

The whooping cough agent Bordetella pertussis colonizes the upper respiratory tract of humans. Its virulence regulon is controlled by the TCS BvgAS. At $37^{\circ} \mathrm{C}$ and in laboratory growth conditions, the BvgAS system is activated, leading to the transcription of a number of genes coding for virulence factors, necessary for infection [3]. In contrast to most two-component sensor-kinases,

\section{Biomed Central}

(c) 2013 Dupré et al.; licensee BioMed Central Ltd. This is an Open Access article distributed under the terms of the Creative Commons Attribution License (http://creativecommons.org/licenses/by/2.0), which permits unrestricted use, distribution, and reproduction in any medium, provided the original work is properly cited. 
BvgS appears to be active in its basal state. Switching to the avirulent $\mathrm{Bvg}^{-}$phase can be triggered by the addition of chemical modulators, such as nicotinate or sulfate ions. However, the authentic negative modulators that might act at specific stage(s) of the bacterium's life cycle remain to be identified. BvgS is a hybrid sensor-kinase harboring several cytoplasmic domains that mediate a complex phospho-transfer cascade [4]. It also contains three potential perception domains, two periplasmic Venus flytrap (VFT) domains in tandem and a cytoplasmic Per/ArnT/Sim (PAS) domain followed by the kinase domain [5]. We have established that the second VFT domain, VFT2, binds nicotinate and related negative modulator molecules [6]. BvgS is the prototype for VFTcontaining sensor-kinases mostly found in Proteobacteria whose molecular mechanisms are poorly understood.

In this work, we characterized the PAS domain of BvgS $\left(\mathrm{PAS}_{\mathrm{Bvg}}\right)$. PAS domains are structurally conserved, 100- to 120-residue-long signaling modules with sensory and regulatory functions, present in kinases, chemoreceptors and other types of proteins in all branches of the phylogenetic tree $[7,8]$. They are composed of a central, five-stranded anti-parallel $\beta$ sheet flanked by $\alpha$ helices. Many PAS domains appear to form dimers in vitro and in vivo [8]. A subset of PAS domains harbors heme, flavine nucleotide or other cofactors for perception of physical parameters such as light or $\mathrm{O}_{2}$ [9]. Some cytoplasmic PAS domains appear to modulate signal transmission rather than to directly perceive a signal $[8,10,11]$. Finally, some PAS domains, including the periplasmic 'PDC' (PhoP/DcuS/CitA) domains found in many bacterial TCS sensor-kinases bind small chemical ligands, which triggers signal transduction [12-15]. Although the presence of a PAS domain in BvgS has been recognized for over 20 years [16,17], its role is still unknown. Here, we show that this domain is required for transmission of signals from the periplasm.

\section{Methods}

\section{Strains and plasmids}

The sequence coding for the PAS core domain was amplified by PCR using the PAScore UP and PAScore LO oligonucleotides as primers (see Additional file 1: Table S1). The amplicon was inserted in pCRII-TOPO (Invitrogen) and sequenced. It was then introduced as a BamHI-HindIII fragment into the corresponding sites of pQE-30 (Qiagen). The resulting plasmid encodes the $\mathrm{PAS}_{\mathrm{Bvg}}$ core with an $\mathrm{N}$-terminal His tag. Next, two longer constructs were prepared using the primers PAS His UP and PAS His LO and PAS GB1 UP and PAS GB1 LO. The first amplicon was introduced into pQE30 as a BglII-HindIII fragment, and the other was introduced into pGEV2 [18] as a BamHI-XhoI fragment. The first plasmid codes for $\mathrm{PAS}_{\mathrm{Bvg}}$ flanked by its $\mathrm{N}$ - and $\mathrm{C}$-terminal helices and with an N-terminal 6-His tag. The second codes for a fusion between the GB1 domain and the same BvgS fragment. Finally, sequences coding for $\mathrm{PAS}_{\mathrm{Bvg}}$ recombinant proteins of various lengths were amplified by PCR using a combination of the following primers: PAS N1UP, PAS N2UP or PAS N3UP and PAS C1LO, PAS C2LO or PAS C3LO (Additional file 1: Table S1). The amplicons were restricted as BsaI fragments, introduced into the corresponding sites of the pASK-IBA35+ vector (IBA) and sequenced. The resulting plasmids encode recombinant PAS $_{\text {Bvg }}$ proteins with an $\mathrm{N}$-terminal His tag in all cases.

Selected residues were replaced by site-directed mutagenesis as described in [19]. Briefly, the Bvg-BglII and Bvg-Xba primers were used with the 'LO' and 'UP' primers of each pair of mutagenic oligonucleotides to perform overlapping PCRs (Additional file 1: Table S1; the names of the mutagenic oligonucleotides relate to the corresponding substitutions). After verification of the sequences, the mutated fragments were exchanged for their wild type (wt) counterparts in a plasmid that contains most of the $b v g A S$ operon in tandem restriction cassettes [19]. The bvgS sequence coded by that plasmid corresponds to that of Tohama I BP1877, except that a Glu codon is found at position 705, as found in most other B. pertussis strains [19]. The mutations were then introduced into the chromosome of $\mathrm{BPSM}_{\triangle b v g A S}$, a Tohama I derivative harboring a large deletion in the bvgAS operon, by using allelic exchange as described [19]. Finally, a $p t x-l a c Z$ transcriptional fusion was generated in each of the recombinant strains using pFUS2 [20].

The virulent $\mathrm{BPSM}_{\mathrm{E} 705}$ strain (wt control) and the avirulent B. pertussis BPSM $\Delta b v g S$ were described in [19]. BPSM $\triangle b v g A$ harbour a chromosomal deletion of $b v g A$. It was constructed by allelic replacement using homologous recombination as follows. DNA fragments flanking the $b v g A$ gene were amplified from the BPSM chromosome using the pairs of oligonucleotides BvgA-UP1 and BvgALO1, and BvgA-UP2 and BvgA-LO2, respectively. The amplicons were used as templates for an overlapping PCR, and the resulting amplicon was introduced as an XbaI-HindIII restriction fragment into pSS1129 restricted with the same enzymes [21]. The resulting suicide plasmid was used for allelic replacement as described [21].

To introduce the substitutions of interest into the recombinant protein, the N2C3 UP and N2C3 LO primers were used to amplify the relevant gene portion from the mutagenized plasmids described above. The amplicons were then introduced into pASK-IBA35+ in the same manner as for the wt gene fragment.

\section{Protein production and purification}

Productions of the $\mathrm{PAS}_{\mathrm{BvgS}}$ core from the $\mathrm{pQE}$ and pGEV derivatives were performed in Escherichia coli 
SG13009(pREP4) (Qiagen) and BL21(DE3), respectively. pREP4 harbors a lacl $^{Q}$ gene for repression of the lac promoter prior to induction with IPTG.

A number of conditions were tested to optimize protein production, by varying the temperature of the cultures, the absorbance at $600 \mathrm{~nm}$ of the culture at the time of induction, the concentration of inducer and the duration of the induction. Production of the 9 recombinant proteins from the PIBA derivatives was performed in E. coli BL21 (DE3). A number of inductions conditions were also tested, and the following one was identified as the most suitable. A $50-\mathrm{ml}$ overnight culture in LB medium supplemented with $150 \mu \mathrm{g} / \mathrm{ml}$ ampicillin (LB$\mathrm{Amp}_{100}$ ) was used to inoculate 1 liter of LB-Amp 150 to an $\mathrm{OD}_{600}$ of 0.05 . The culture was incubated at $37^{\circ} \mathrm{C}$ in a rotary shaker at $220 \mathrm{rpm}$. Expression of recombinant $\mathrm{PAS}_{\mathrm{Bvg}}$ was induced at an $\mathrm{OD}_{600}$ of 0.4 by the addition of $200 \mu \mathrm{g} / \mathrm{L}$ anhydrotetracycline (IBA). After $5 \mathrm{~h}$ of incubation under the same conditions, the cells were harvested by centrifugation at $8,000 \times \mathrm{g}$ for $20 \mathrm{~min}$ at $4^{\circ} \mathrm{C}$. Hemin (Sigma) or 5 -aminolevulinic acid (Sigma) were added at a concentration of $10 \mathrm{mM}$ one hour before induction in the relevant cultures. For $\mathrm{N} 2 \mathrm{C} 3$ production at $16^{\circ} \mathrm{C}$, the cultures were grown at $37^{\circ} \mathrm{C}$ until they reached an $\mathrm{OD}_{600}$ of 0.4 , then switched to $16^{\circ} \mathrm{C} 30 \mathrm{~min}$ before addition of the inducer. Induction was performed for 16 hours.

In all cases, the cell pellets were resuspended in $10 \mathrm{mM}$ Tris- $\mathrm{HCl}$ (pH 7.5), $150 \mathrm{mM} \mathrm{NaCl}, 10 \mathrm{mM}$ imidazole (binding buffer) with $5 \mu \mathrm{g} / \mathrm{ml}$ of DNase I (Sigma) and EDTA-free protease inhibitor cocktail (Roche). Cells were disrupted by three passages in a French pressure cell, and the bacterial debris was removed by centrifugation for $20 \mathrm{~min}$ at $10,000 \times g$. The supernatant was loaded onto a $\mathrm{Ni}^{2+}$-Sepharose affinity column (GE Life Sciences) pre-equilibrated with the binding buffer. Two washing steps were performed by using successively $10 \mathrm{mM}$ and $50 \mathrm{mM}$ of imidazole in the binding buffer, followed by an elution step with $200 \mathrm{mM}$ imidazole. The protein was further purified by gel filtration in $10 \mathrm{mM}$ Tris- $\mathrm{HCl}$ (pH 7.5), $150 \mathrm{mM} \mathrm{NaCl}$ through a HiLoad 16/60 Superdex 75 column (GE Healthcare). All purification steps were carried out at $4^{\circ} \mathrm{C}$ or $12^{\circ} \mathrm{C}$.

\section{Protein analyses}

Mass spectrometry analyses were performed on an ESIQ-TOF spectrometer (Waters, Micromass) in positive ion mode by GIGA Proteomics at the University of Liège, Belgium. Purified N2C3 was used at a concentration of $10 \mu \mathrm{M}$ in $27 \mathrm{mM}$ ammonium acetate for native conditions, or in $31.25 \mathrm{mM}$ ammonium acetate, $30 \%$ acetonitrile and $0.5 \%$ formic acid for denaturing conditions.

The delipidation treatment of the purified protein was performed as described in [22]. The protein solution $(4 \mathrm{mg} / \mathrm{ml})$ was incubated with $1 \mathrm{ml}$ of LIPIDEX 1000 matrix (Perkin Elmer) previously equilibrated in the gel filtration buffer, for 1 hour at $37^{\circ} \mathrm{C}$ under gentle agitation. The mixture was centrifuged, and the supernatant was collected and applied to the same amount of fresh LIPIDEX 1000 matrix. The incubation step was performed 6 times in total. Thermal denaturation was performed in 96-wells plate with $15 \mu \mathrm{l}$ per well of a $30 \mu \mathrm{M}$ protein solution and $4 \times$ NanoOrange $^{\circ}$ (Invitrogen) diluted 125 folds from a $500 \times$ stock solution [23]. The plates were heated from $25^{\circ} \mathrm{C}$ to $85^{\circ} \mathrm{C}$ with a ramp rate of $0.07^{\circ} \mathrm{C} / \mathrm{s}$ and read by a thermocycler (LightCycler 480 II, Roche) using excitation and emission wavelengths of $465 \mathrm{~nm}$ and $510 \mathrm{~nm}$, respectively. The Tms were determined using the LightCycler480 Software. The experiments were performed two or three times at least in triplicate. The statistical analyses were performed using the unpaired $t$ test of the Graphpad PRISM software.

For the crystallogenesis attempts, purified $\mathrm{PAS}_{\mathrm{Bvg}}$ proteins $(\mathrm{N} 2 \mathrm{C} 2, \mathrm{~N} 2 \mathrm{C} 3, \mathrm{~N} 3 \mathrm{C} 2$ and $\mathrm{N} 3 \mathrm{C} 3)$ were concentrated using a centrifugal filter unit (Ultracel ${ }^{\circ} 10 \mathrm{kDa}$ membrane, Amicon ${ }^{\circ}$ Ultra, Millipore, Billerica, MA). Crystallization screening was carried out using the sittingdrop, vapor-diffusion technique in 96-well microplates. Trays were set using a Phenix crystallization robot (Art Robbins instrument) and commercial crystallization kits (HR-Index, HR-AMSO4, HR-Cryst1\&2, HR-Cryo from Hampton Research, Nextal-JCSG + from QIAGEN, Proplex and PACT from Molecular Dimensions). The drops were set up by mixing equal volumes $(0.1 \mu \mathrm{l})$ of the protein and the precipitant solutions equilibrated against $75 \mu \mathrm{l}$ of the precipitant solution. The protein concentrations ranged from 10 to $80 \mathrm{mg} / \mathrm{ml}$ for $\mathrm{PAS}_{\mathrm{Bvg}} \mathrm{N} 2 \mathrm{C} 3$ and $\mathrm{N} 2 \mathrm{C} 2$ and from 10 to $30 \mathrm{mg} / \mathrm{ml}$ for PAS $\mathrm{Bvg}_{\text {Bvg }} \mathrm{N} 3 \mathrm{C} 2$ and N3C3.

To prepare the membrane fractions of the various $B$. pertussis strains, the bacteria were grown in modified Stainer-Scholte medium (SS) [24] containing $100 \mu \mathrm{g} / \mathrm{ml}$ streptomycin and $10 \mu \mathrm{g} / \mathrm{ml}$ gentamycin. After $24 \mathrm{~h}$ at $37^{\circ} \mathrm{C}$ under rotating agitation $(220 \mathrm{rpm})$ cells were harvested by centrifugation, resuspended in phosphatebuffered saline (PBS) to an $\mathrm{OD}_{600}$ of 5 and broken using a Hybaid Ribolyser apparatus (30 $\mathrm{s}$ at speed 6 in tubes containing $0.1 \mathrm{~mm}$ silica spheres as the lysing matrix). The lysates were clarified by centrifugation $(8000 \times g$, 10 minutes), and the membrane fractions were pelleted from $1 \mathrm{ml}$ of supernatants by ultracentrifugation $(90$ $000 \times g, 1$ hour). The pellets were resuspended in $100 \mu \mathrm{l}$ PBS and used for denaturing electrophoresis in $4-8 \%$ gradient polyacrylamide gels (Novex, Life Technologies). The proteins were then transferred electrophoretically to nitrocellulose membranes for immunoblotting. Poly clonal antibodies against BvgS were raised in rats (Eurogentec, Belgium) and used at a 1:500 dilution in PBS $+0.1 \%$ Tween 20 . The secondary antibody was an anti-rat immunoglobulin- alkaline phosphatase conjugate 
(Promega) at a 1:7,500 dilution in the same buffer. Revelation of the blots was performed using the BCIP/NBT Color Development Substrate (Promega).

\section{Homology modeling}

A similarity search using PSI-BLAST [25] was performed to find suitable templates. Modeller 9v8 [26] was used to build a model of the structure of the PAS domain of BvgS based on 3BWL. The protein side-chain conformations were predicted using SCWRL4 [27]. The quality of the model was assessed using PROSA II [28]. Molecular structure inspections and illustrations were made using PyMOL (PyMOL Molecular Graphics System, version 1.3, Schrödinger).

\section{$\beta$-galactosidase activities}

The various $B$. pertussis strains harboring specific mutations in $b v g S$ and a $p t x-l a c Z$ fusion were grown in modified SS medium containing $100 \mu \mathrm{g} / \mathrm{ml}$ streptomycin and $10 \mu \mathrm{g} / \mathrm{ml}$ gentamycin. After $24 \mathrm{~h}$ at $37^{\circ} \mathrm{C}$ under rotating agitation as above, the bacterial suspension was used to initiate cultures in $10 \mathrm{ml}$ of medium either not supplemented or containing the desired concentration of modulators. The inoculation volume was adapted to compensate for slower growth in the presence of high concentrations of nicotinate. The bacteria were grown until the cultures reached an $\mathrm{OD}_{600}$ of 1.5 , harvested by centrifugation, resuspended in $\mathrm{Z}$ buffer $\left(60 \mathrm{mM} \mathrm{Na} 2 \mathrm{HPO}_{4}, 40 \mathrm{mM} \mathrm{NaH} \mathrm{PO}_{4}, 10 \mathrm{mM} \mathrm{KCl}\right.$, $1 \mathrm{mM} \mathrm{MgSO}_{4}$ and 2,7 $\mathrm{ml}$ of 2-mercaptoethanol per liter added immediately before use) to an $\mathrm{OD}_{600}$ of 5 and broken as described above. $\beta$-galactosidase activities were determined as described [19]. The experiments were performed in triplicate, and statistical analyses were conducted as above. The ptx operon codes for pertussis toxin, a virulence factor whose expression is positively regulated by BvgAS. The $p t x-$ lac $Z$ transcriptional fusion interrupts the first gene of the operon and places lac $Z$ under the control of the Bvg-regulated ptx promoter. Thus, the levels of $\beta$ galactosidase activity measured after growth in virulent, $\mathrm{Bvg}^{+}$conditions reflect the activity of BvgS, while those under modulating conditions reflect the ability of $\mathrm{BvgS}$ to respond to the negative modulators.

\section{Results}

\section{Production of recombinant PAS proteins}

Among the hundreds of predicted VFT sensor-kinases many, including BvgS, harbor in their cytoplasmic moiety PAS, GAF, receiver or Hpt domains in addition to the His-kinase module [5]. When present, the PAS domain most frequently precedes the kinase domain.

In order to study its function in BvgS and perform its biochemical characterization, we produced $\mathrm{PAS}_{\mathrm{Bvg}}$ as a recombinant protein in E. coli. The PAS core domain (whose limits are given by the $\mathrm{NO}$ and $\mathrm{C} 0$ marks in Figure 1) carrying an N-terminal 6-His tag was insoluble. Thus, we produced longer recombinant proteins that also encompass the $\mathrm{N}$ - and C-terminal extensions flanking the PAS core and predicted to form $\alpha$ helices (marked NL and CL in Figure 1), as fusions either with an $\mathrm{N}$-terminal 6-His tag or an $\mathrm{N}$-terminal GB1 domain. Because the first protein was totally insoluble and the second was soluble and monomeric, we suspected that the latter might be partly misfolded but protected from aggregation by the GB1 domain, which is known to enhance solubility of its fusion partner [18]. Therefore, we used a more systematic approach by designing several constructs of varying lengths (marked N1, N2, N3, C1, C2 and C3 in Figure 1), and we expressed them under the control of the tightly regulated tet promoter. Among these proteins, only N2C2, N2C3, N3C2 and $\mathrm{N} 3 \mathrm{C} 3$ were produced in good amounts in essentially soluble forms and could be purified. Size-exclusion chromatography indicated the exclusive formation of dimers for all four of them (not shown). Denaturation of the recombinant proteins using a thermal shift assay (TSA) [23] indicated melting temperatures $(\mathrm{Tm})$ of $61-70^{\circ} \mathrm{C}$, arguing that they are properly folded (Table 1 ). $\mathrm{N} 2 \mathrm{C} 2$ and $\mathrm{N} 2 \mathrm{C} 3$ had the highest denaturation temperatures. Both contain relatively long extensions on both sides of the PAS core (Figure 1). The reason why the N1 constructs were poorly soluble is unclear. Inspection of the sequence shows the presence of several positively charged residues at their $\mathrm{N}$ terminus, leading us to speculate that dimer formation might be destabilized by electrostatic repulsion between the $\mathrm{N}$ termini of the two chains.

Thus, recombinant $\mathrm{PAS}_{\mathrm{Bvg}}$ produced in E. coli is dimeric, and the flanking helices predicted to form coils that precede and follow the PAS core appear to stabilize it. Most kinases of two-component systems work as dimers, and therefore the finding that the domain immediately preceding the kinase in BvgS also dimerises is not unexpected. In addition, PAS domains of other proteins frequently form dimers. It is thus likely that $\mathrm{PAS}_{\mathrm{Bvg}}$ dimerises in the context of the full-length protein as well.

\section{$\mathrm{PAS}_{\mathrm{Bvg}}$ structural model}

We next attempted to obtain the X-ray structure of recombinant $\mathrm{PAS}_{\mathrm{Bvg}}$. However, none of the four soluble recombinant proteins yielded diffracting crystals in spite of repeated attempts. We therefore searched for a homolog of known structure in the protein structure database, on the basis of which a 3-dimensional model of $\mathrm{PAS}_{\mathrm{Bvg}}$ could be built. The closest PAS domain of known structure, $\mathrm{PAS}_{\mathrm{Hm}}$ (pdb code: 3BWL), found in an Htr-like protein of Haloarcula marismortui has been crystallized 


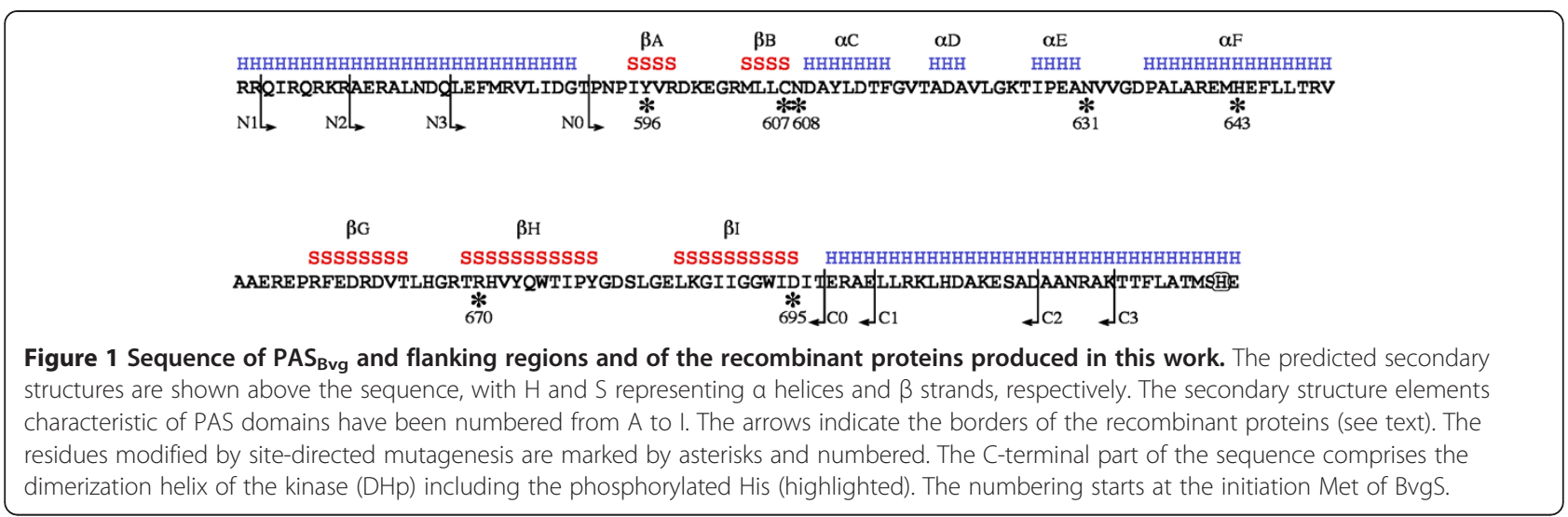

in a structural genomic program. $\mathrm{PAS}_{\mathrm{Hm}}$ is dimeric and harbors a long $\alpha$ helix $\mathrm{N}$ terminal to the PAS core, like that predicted to link the transmembrane segment and PAS core domain in BvgS. Interestingly, the physicochemical properties of these N-terminal flanking $\alpha$ helices are very similar between $\mathrm{PAS}_{\mathrm{Hm}}$ and $\mathrm{PAS}_{\mathrm{Bvg}}$, with a number of charged residues in both cases. In the fulllength protein of $H$. marismortui, the $\mathrm{PAS}_{\mathrm{Hm}}$ domain is followed by a predicted $\alpha$ helix and a histidine-kinase domain, like in BvgS. However, $\mathrm{PAS}_{\mathrm{Hm}}$ was crystallized

Table 1 Relevant features of the proteins produced in this work

\begin{tabular}{cccc}
\hline Name & Residue range $^{*}$ & Calculated $\mathbf{~ M W ~ ( D a ) ~}^{\#}$ & Tm $\left({ }^{\circ} \mathbf{C}\right)$ \\
\hline PAS core & $592-697$ & 13,193 & nd \\
N1C1 & $566-701$ & 16,960 & nd \\
N1C2 & $566-714$ & 18,438 & nd \\
N1C3 & $566-720$ & 19,049 & nd \\
N2C1 & $573-701$ & 15,994 & nd \\
N2C2 & $573-714$ & 17,472 & $69.7 \pm 0.2$ \\
N2C3 & $573-720$ & 18,083 & $70.5 \pm 0.3$ \\
N3C1 & $581-701$ & 15,096 & $n d$ \\
N3C2 & $581-714$ & 16,574 & $63.1 \pm 0.2$ \\
N3C3 & $581-720$ & 17,185 & $61.1 \pm 0.5$ \\
$Y_{596} \mathrm{~A}+\mathrm{N}_{631} \mathrm{~A}$ & $573-720$ & 17,948 & $\mathrm{nd}$ \\
$\mathrm{C}_{607} \mathrm{~A}$ & $573-720$ & 18,051 & $62.3 \pm 0.2$ \\
$\mathrm{~N}_{608} \mathrm{~A}$ & $573-720$ & 18,040 & $\mathrm{nd}$ \\
$\mathrm{N}_{608} \mathrm{~S}$ & $573-720$ & 18,056 & $60.3 \pm 0.6$ \\
$\mathrm{H}_{643} \mathrm{~A}$ & $573-720$ & 18,017 & $63.0 \pm 0.4$ \\
$\mathrm{R}_{670} \mathrm{~A}$ & $573-720$ & 17,998 & $66.8 \pm 0.2$ \\
$\mathrm{D}_{695} \mathrm{~A}$ & $573-720$ & 18,039 & $60.1 \pm 0.1$ \\
\hline
\end{tabular}

* The numbering refers to full-length BvgS starting from the initiation Met residue.

\# The calculated molecular masses (for a monomer) comprise the start linker from the PASK plasmid without the initiation Met (ASRGSHHHHHHGA). For the PAS core the start linker sequence is RGSHHHHHHGS.

nd, not determined (see text).

The Tms of the N2C3 variants were all significantly different $(P<0.01)$ from that of the wt $\mathrm{N} 2 \mathrm{C} 3$ protein. without this C-terminal $\alpha$ helix. The features of $\mathrm{PAS}_{\mathrm{Hm}}-$ dimerisation and the presence of flanking helical extensions at both extremities are in agreement with the predictions and available data for $\mathrm{PAS}_{\mathrm{Bvg}}$, indicating that the former represents a reasonable structural template for the latter.

A structural model of $\mathrm{PAS}_{\mathrm{Bvg}}$ was thus built in silico (Figure 2). According to this model, two monomers form a parallel dimer, with long $\mathrm{N}$-terminal, amphipathic $\alpha$ helices extending upward from the PAS cores. Each $\mathrm{PAS}_{\mathrm{Bvg}}$ core domain is flanked by the last part of the flanking N-terminal $\alpha$ helix of the opposite monomer, thereby forming a swapped dimer. Interactions between these long $\alpha$ helices and between the PAS domains themselves through the backs of their $\beta$ sheets also contribute to the dimeric interface.

\section{Hypothesis of a heme co-factor}

$\mathrm{PAS}_{\mathrm{Bvg}}$ shares sequence similarity, and in particular a conserved His residue, with heme-PAS domains of the $\mathrm{O}_{2}$-sensing FixL proteins of Bradirhizobium japonicum and Sinorhizobium meliloti [29-31]. In FixL this His residue serves as an axial ligand for the heme iron. In the $\mathrm{PAS}_{\mathrm{Bvg}}$ model, the corresponding His residue $\left(\mathrm{His}_{643}\right)$ is located in the long $\alpha$ helix F, with its side chain pointing to the cavity in an appropriate position to interact with a putative heme co-factor (Figure 3). However, the absorbance spectrum of the recombinant $\mathrm{PAS}_{\mathrm{Bvg}}$ proteins did not indicate the presence of a heme moiety and was not modified by the addition of heme after purification (not shown). Furthermore, when production of $\mathrm{PAS}_{\mathrm{Bvg}}$ was performed with the addition of hemin or the heme precursor levulinate to the growth medium, no absorbance peak indicative of a heme protein was observed for the purified protein.

We nevertheless tested the possibility that $\mathrm{PAS}_{\mathrm{Bvg}}$ harbors a heme co-factor or a related molecule when present in the full-length BvgS protein in B. pertussis by replacing $\mathrm{His}_{643}$ with Ala. In bona fide heme-PAS domains, replacement of the His residue abolishes heme 


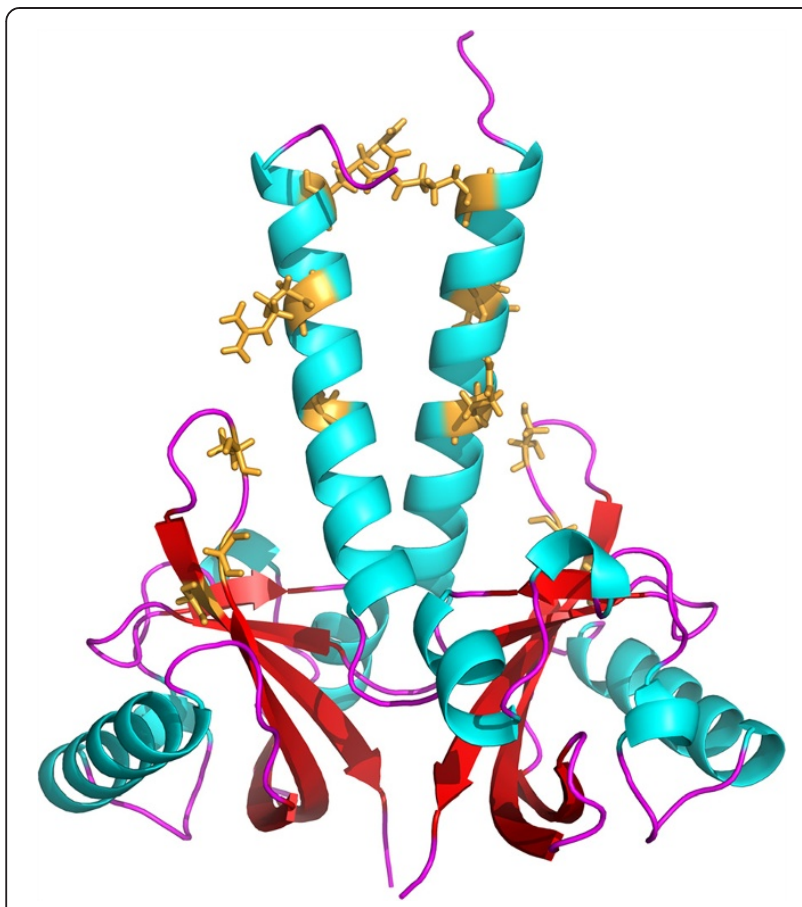

Figure 2 Structural model for $\mathrm{PAS}_{\mathrm{Bvg}}$. The modeled sequence encompasses residues 564-697 of BvgS, thus immediately following the predicted transmembrane segment of BvgS. The segment after the PAS core has not been modeled, because the corresponding segment is absent from the $\mathrm{PAS}_{\mathrm{Hm}} \mathrm{X}$-ray structure. In BvgS this segment is predicted to form an a helix linking the PAS and kinase domains. In yellow are shown residues whose substitutions were previously reported to abolish the responsiveness of BvgS to negative modulation (see discussion).

binding [31]. Because B. pertussis is virulent in aerobic growth conditions, we reasoned that $\mathrm{O}_{2}$ would most likely be a positive signal for BvgS if the PAS domain harbored an $\mathrm{O}_{2}$-sensing heme, and therefore that a substitution abolishing heme binding should inactivate BvgS. The mutation was introduced into the chromosome of the B. pertussis Tohama I derivative BPSM $\mathrm{E}_{\mathrm{E} 05}$ by allelic exchange, and the activity of BvgAS was assessed by using a lac $Z$ reporter under the control of the ptx promoter, which is positively controlled by BvgAS. The mutated strain expressed ß-galactosidase activity at a level similar to that of the strain containing wt BvgS (Figure 4). Interestingly, BvgS $\mathrm{His643Ala}_{\text {was }}$ insensitive to sulfate and nicotinate (Figure 4). Other negative modulators [32] also failed to modulate the activity of the recombinant strain, even at much higher concentrations than those that modulate wild type BvgS (not shown). Thus, the $\mathrm{His}_{643} \mathrm{Ala}$ substitution appears to make BvgS unresponsive to modulation.

The $\mathrm{His}_{643} \mathrm{Ala}$ substitution was also introduced into the $\mathrm{N} 2 \mathrm{C} 3$ recombinant protein, and the $\mathrm{N} 2 \mathrm{C} 3$ variant was purified. Similar to all soluble proteins produced in this work, $\mathrm{N}_{2} \mathrm{C} 3_{\text {His643Ala }}$ was dimeric (not shown). Using the thermal shift assay its Tm was determined to be $7^{\circ} \mathrm{C}$ lower than its wt counterpart (Table 1). Altogether, our data do not support the notion that $\mathrm{PAS}_{\mathrm{Bvg}}$ has a heme cofactor. However, $\mathrm{His}_{643}$ appears to be required for $\mathrm{BvgS}$ response to negative signals, indicating its functional importance. It also contributes to the thermal stability of recombinant $\mathrm{PAS}_{\mathrm{Bvg}}$.

\section{Role of the PAS cavity}

To probe for the presence of another potential co-factor or ligand in the $\mathrm{PAS}_{\mathrm{Bvg}}$ cavity, electron spray ionization mass spectrometry was performed in native conditions using the $\mathrm{N} 2 \mathrm{C} 3$ variant. This analysis independently confirmed the dimeric nature of the recombinant protein, with a mass of $36,171 \pm 3.6 \mathrm{Da}$, and ruled out the presence of a covalent ligand associated with recombinant $\mathrm{PAS}_{\text {Bvg. }}$. A mass spectrometry analysis performed under denaturing conditions yielded a mass of $18,084 \pm 1.8 \mathrm{Da}$, close to the calculated value $(18.083 \mathrm{kDa}$ excluding the initiation methionine).

We then targeted other residues of the PAS ${ }_{\text {Bvg }}$ cavity between the inner surface of the $\beta$ sheet and the helices of the PAS core. These residues were chosen on the basis of the structural model and of sequence alignments. $\mathrm{PAS}_{\mathrm{Bvg}}$ harbours a unique Cys residue $\left(\mathrm{Cys}_{607}\right)$ in a short loop bordering the cavity. Cys residues have been implicated in co-factor binding in other types of PAS (e.g. LOV domains) [33]. In addition, they may be involved in the perception of redox signals [34], a function that has been proposed for BvgS [15]. The substitution of Cys $_{607}$ by an Ala residue in full-length BvgS did not modify its basal activity in B. pertussis (Figure 4). Interestingly, $\mathrm{BvgS}_{\text {Cys607Ala }}$ was non-responsive to modulation by nicotinate, whereas it remained responsive to modulation by $\mathrm{MgSO}_{4}$. The responses to other modulators related to nicotinic acid were also tested (not shown). The activity of $\mathrm{BvgS}_{\mathrm{Cys} 607 \mathrm{Ala}}$ was modulated only at much higher modulator concentrations than those required for the wild type control, indicating that this variant has an intermediate rather than a non-responsive modulation phenotype.

The corresponding recombinant protein was produced, purified and analyzed by TSA. Its Tm was $8^{\circ} \mathrm{C}$ lower than that of wt N2C3 (Table 1). Altogether, these results identified a second residue of the $\mathrm{PAS}_{\mathrm{Bvg}}$ cavity whose replacement decreases both the denaturation temperature of the recombinant protein and the ability of BvgS to respond to nicotinic acid and related molecules that are perceived by the periplasmic domain.

The structure of the PAS domain of the Mycobacterium tuberculosis Rv1364c protein (pdb code 3K3C) shows an Arg residue in the cavity that is essential for the binding of a C16-fatty acid ligand [22]. An Arg residue is found in $\mathrm{PAS}_{\mathrm{Bvg}}$ at a corresponding position $\left(\mathrm{Arg}_{670}\right)$, and its side chain appears to be oriented in the same manner in the 

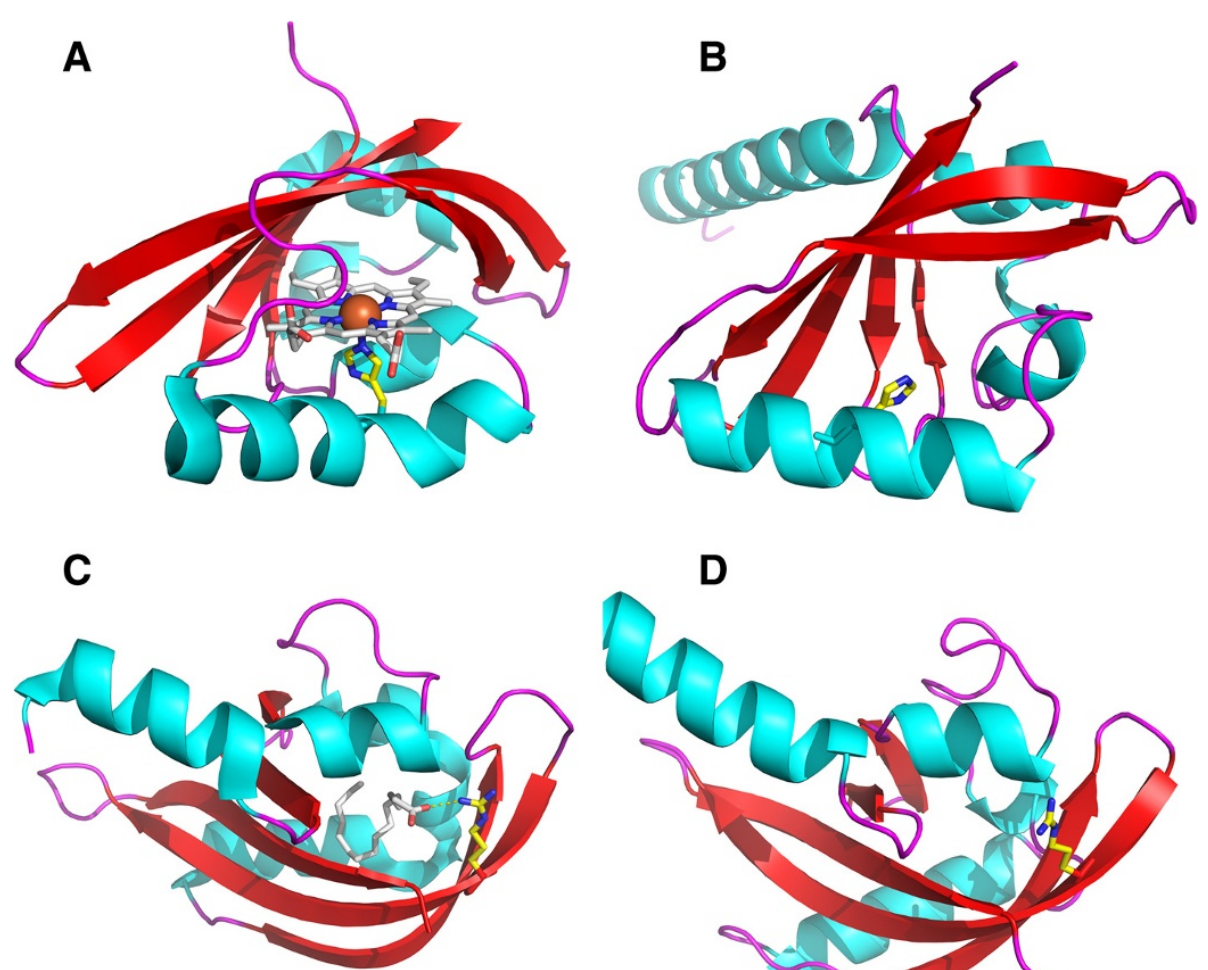

D

E

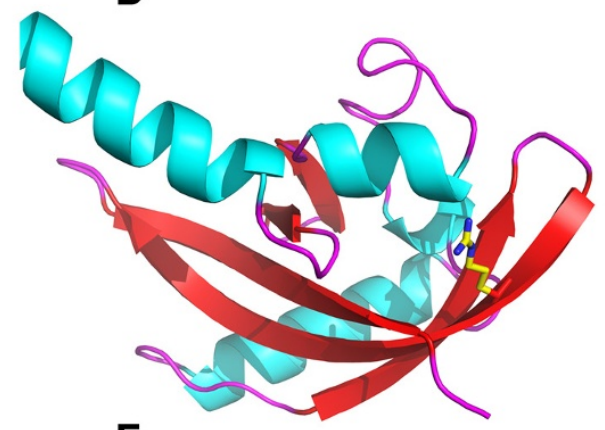

$\mathbf{F}$
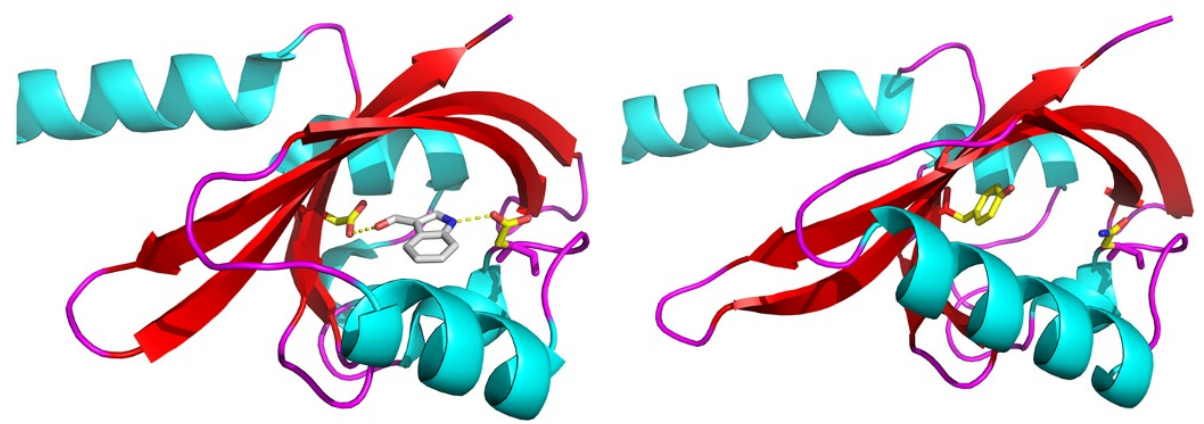

Figure 3 Close-up views of regions targeted by site-directed mutagenesis. The structures of PAS domains used to select the residues to replace are shown on the left $(\mathbf{A}, \mathbf{C}, \mathbf{E})$, and the corresponding views of the $\mathrm{PAS}_{\mathrm{Bvg}}$ model are shown on the right $(\mathbf{B}, \mathbf{D}, \mathbf{F})$. The residues that were replaced are colored yellow. A, FixL $L_{B j}$ PAS domain (pdb code: 1DRM), with the heme colored grey. C, PAS domain of the M. tuberculosis Rv1364C

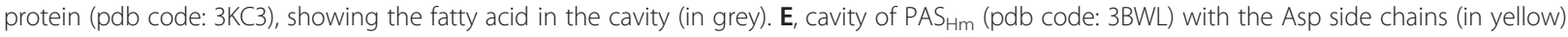
pointing to the $1 \mathrm{H}$-indole-3 carbaldehyde ligand (in grey). In $\mathrm{PAS}_{\mathrm{Bvg}}(\mathbf{F})$ the corresponding residues are $\mathrm{Tyr}_{596}$ and $\mathrm{Asn}_{631}$.

$\mathrm{PAS}_{\mathrm{Bvg}}$ model as that in $\mathrm{PAS}_{\mathrm{Rv} 1364 \mathrm{c}}$ (Figure 3). In the latter protein, the ligand was identified only when the recombinant bacteria were grown at low temperatures $\left(16^{\circ} \mathrm{C}\right)[22]$. We therefore purified $\mathrm{N} 2 \mathrm{C} 3$ from E. coli grown at $16^{\circ} \mathrm{C}$ and subjected it to thermal shift analysis before and after delipidation, to test whether the loss of a putative ligand might destabilize the PAS $_{\text {Bvg }}$ domain. However, the Tm of $\mathrm{N} 2 \mathrm{C} 3$ was not affected by this treatment, and it was similar to that measured for the protein grown at $37^{\circ} \mathrm{C}$ (not shown). Similarly, the Tm of the N2C3 protein harboring the $\operatorname{Arg}_{670}$ Ala substitution was only moderately decreased compared to that of its wt counterpart (Table 1). We also introduced the $\operatorname{Arg}_{670}$ Ala substitution in full-length BvgS, which did not affect its activity in B. pertussis or its ability to respond to negative signals (Figure 4). These observations thus rule out a major function for this residue in PAS $_{\text {Bvg. }}$.

More drastic changes in the PAS cavity were next engineered. In the 3BWL structure, the side chains of two Asp residues bind a fortuitously trapped $1 \mathrm{H}$-indole- 3 carbaldehyde ligand in the PAS cavity. The side chains of the residues at those positions are frequently involved in ligand binding by other PAS domains (our observations), and in the $\mathrm{PAS}_{\mathrm{Bvg}}$ cavity these positions are occupied by 


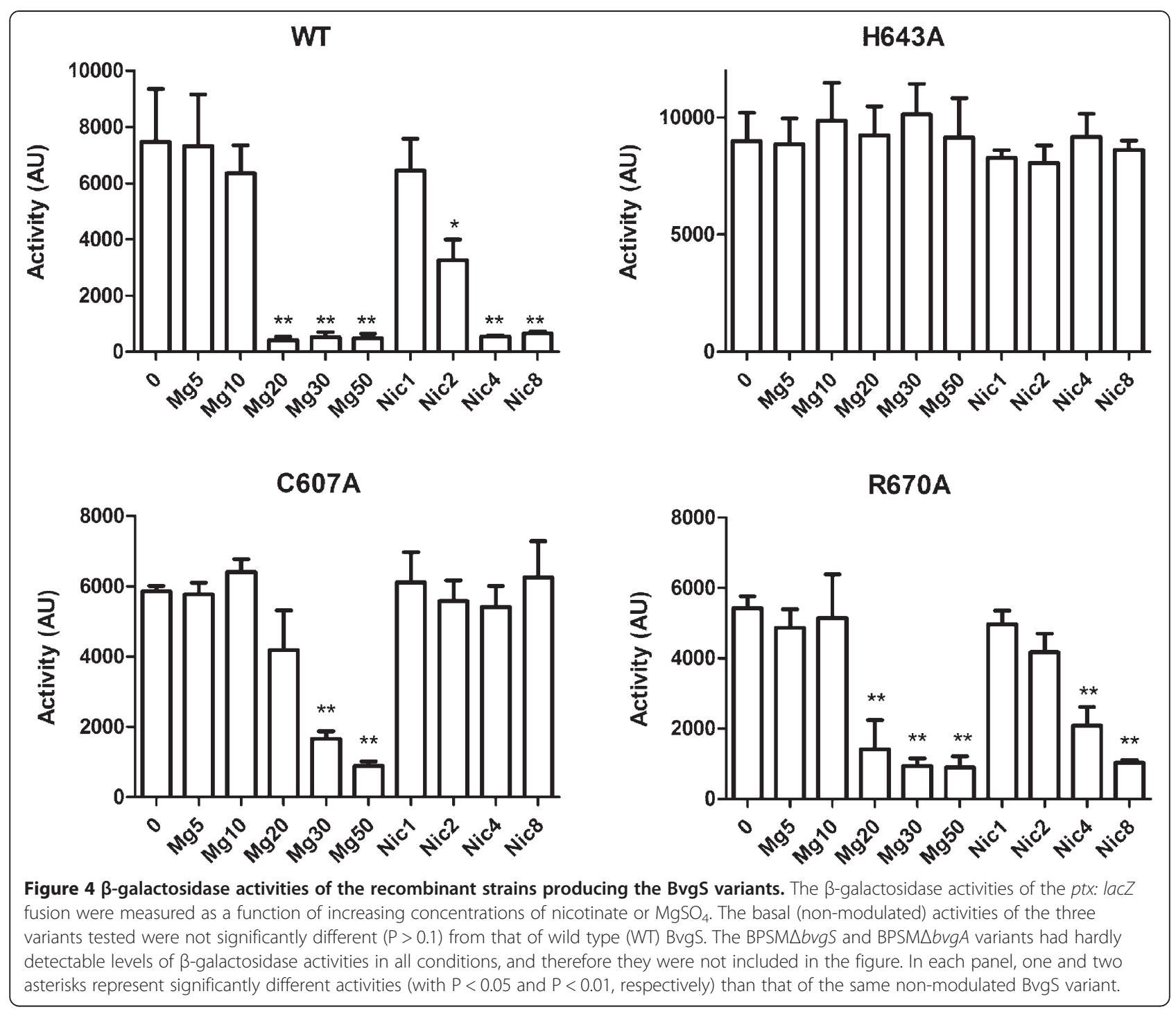

$\mathrm{Tyr}_{596}$ and $\mathrm{Asn}_{631}$ (Figure 3). They were replaced together by Ala in full-length BvgS. BvgS in the resulting B. pertussis recombinant strain was totally inactive (not shown). We thus verified that BvgS $S_{\text {Tyr596Ala+Asn631Ala }}$ was produced in a stable form in the recombinant $B$. pertussis strain by preparing membrane extracts and subjecting them to immuno-blotting using polyclonal anti-BvgS antibodies (Figure 5). The protein was detected, showing that the substitutions did not disrupt full-length BvgS or cause its proteolytic degradation but affected its function.

We next determined the effect of the $\mathrm{Tyr}_{596} \mathrm{Ala}+$ Asn $_{631}$ Ala substitutions on the thermal stability of the recombinant protein. Surprisingly, although N2

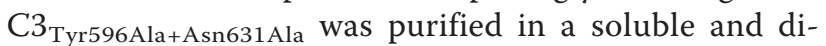
meric form in good amounts, no cooperative denaturation profile was obtained by TSA, and thus no Tm could be calculated. This suggested a significantly looser structure of the PAS core even at lower temperatures. The observations that the joint replacements of $\mathrm{Tyr}_{596}$ and

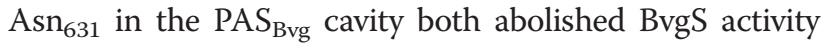
and considerably destabilized $\mathrm{PAS}_{\mathrm{Bvg}}$ argue that the structural stability of the PAS core domain is important for BvgS function. Of note, mutations in the PAS core have been shown to affect the stability and function of other PAS domains as well [35,36].

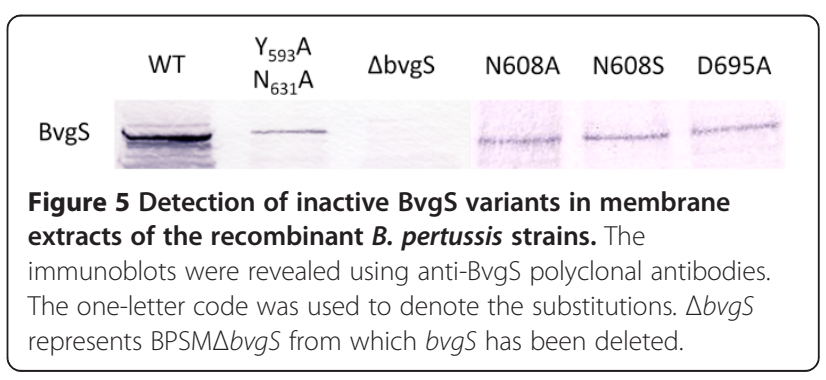




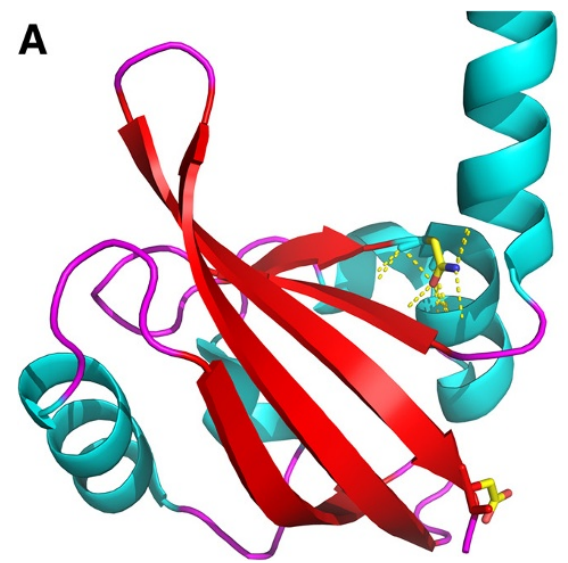

B

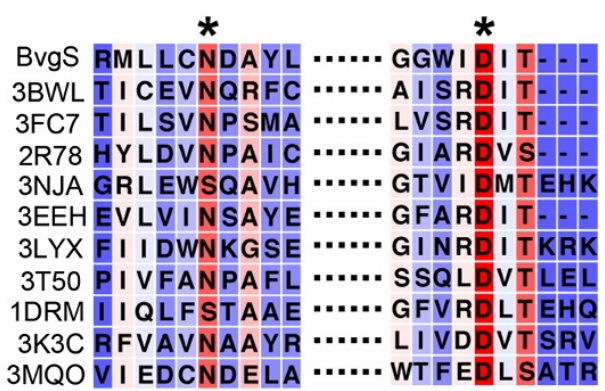

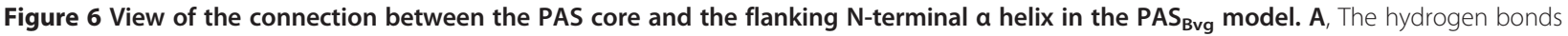
between the conserved Asn residue and the PAS core and N-terminal a helix are shown in stippled lines. Because the C-terminal a helix is absent from the model, the connections of the conserved Asp residue with the flanking C-terminal a helix could not be represented. B, Sequence alignments of these conserved regions are shown in two blocks on the right-hand side of the figure, with the pdb code numbers of the PAS proteins used for the alignment. The conserved Asn/Ser and Asp residues are denoted with asterisks.

\section{PAS coupling with flanking regions}

Based on those results, we hypothesized that a major function of the PAS domain is to maintain - and perhaps to amplify- conformational signals coming from the periplasmic moiety of BvgS to the kinase domain, thus requiring a tightly folded PAS core properly connected to the upstream and downstream $\alpha$ helices. To test this hypothesis, we modified residues that couple the PAS domain to its flanking helices and determined the effects of these replacements on BvgS activity. In the $\mathrm{PAS}_{\mathrm{Hm}}$ structure, a highly conserved Asn residue corresponding to $\mathrm{Asn}_{608}$ in BvgS forms hydrogen bonds within the PAS core and docks the core to the flanking $\mathrm{N}$-terminal $\alpha$ helix (Figure 6). This conserved Asn residue is critical for signaling in PAS proteins such as PYP of Halorhodospira halophila and Aer of Escherichia coli [36,37]. In many PAS domains, a conserved $\mathrm{D}(\mathrm{I} / \mathrm{V} / \mathrm{L}) \mathrm{T}$ motif terminates the PAS core, whose Asp and Thr side chains make interactions that couple it with its flanking $\mathrm{C}$-terminal $\alpha$ helix and effector domain downstream $[8,38]$ (Figure 6). The corresponding Asp residue in $\mathrm{PAS}_{\mathrm{Bvg}}$ is $\mathrm{Asp}_{695}$. To determine the importance of these motifs in BvgS, $\mathrm{Asn}_{608}$ and $\mathrm{Asp}_{695}$ were separately replaced by Ala in full-length $\mathrm{BvgS}$, and $\mathrm{Asn}_{608}$ was also replaced by Ser to maintain some $\mathrm{H}$-bonding capability of the side chain. Of note, a Ser residue is naturally found at this position in certain PAS domains (Figure 6). All three substitutions had dramatic effects on Bvg activity in $B$. pertussis, making the protein inactive in all three cases (not shown). The three variants were nevertheless detected in membrane extracts of the recombinant strains (Figure 5). Thus, the corresponding substitutions abolished the function of BvgS but did not hamper its membrane localization nor cause its degradation.
To determine whether these substitutions affected the $\mathrm{PAS}_{\mathrm{Bvg}}$ structural integrity, they were introduced into the recombinant $\mathrm{N} 2 \mathrm{C} 3$ protein, and the thermal stabilities of the three variants were determined (Table 1). The $\mathrm{N} 2 \mathrm{C} 3_{\mathrm{Asn} 608 \mathrm{Ala}}$ protein was produced in very low amounts, suggesting that the substitution considerably affects its structural integrity. The soluble fraction of the protein was dimeric but had a tendency to precipitate, and therefore it could not be analyzed further. In contrast, the other two proteins were produced in reasonable amounts although lower than that of wt $\mathrm{PAS}_{\mathrm{BvgS}}$ in soluble, dimeric forms, and they were relatively stable over time, suggesting that they were properly folded. Nevertheless, their Tms were more than $10^{\circ} \mathrm{C}$ lower than that of the corresponding wt protein (Table 1). Thus, disconnecting the PAS domain from the flanking helices both abolishes BvgS activity and significantly decreases the stability of recombinant $\mathrm{PAS}_{\mathrm{Bvg}}$. The loss of BvgS activity seems to correlate with significantly looser PAS domain structures.

\section{Discussion}

Over 20,000 PAS domains have been identified in different proteins. They are essentially involved in regulation or sensing. In the family of VFT-containing sensorkinases of which BvgS is a prototype, PAS domains are frequently found between the transmembrane segment and the kinase domain. Sequences of the $b v g A S$ locus from a number of $B$. pertussis, Bordetella bronchiseptica and Bordetella parapertussis isolates have shown the remarkable conservation of the PAS domain in BvgS, supporting the idea that it is functionally important [19]. In this work, we identified specific amino acid residues 
in the PAS domain whose substitutions abolish BvgS activity. They map to three different locations: at the interfaces between the PAS core and its flanking $\mathrm{N}$ terminal and $\mathrm{C}$-terminal $\alpha$ helices, and in the PAS cavity. These results support a key transmission function for the PAS domain in BvgS, related to its critical position between the periplasmic and kinase domains. The PAS domain in BvgS needs to be tightly folded to fulfill this role, because significantly loosening the PAS core or its connections with upstream and downstream helices dramatically affects BvgS activity.

We found that the $\mathrm{PAS}_{\mathrm{Bvg}}$ domain dimerises in E. coli, and we propose that it does so in full-length BvgS as well. Dimer formation is consistent with earlier findings that the kinase domain of BvgS dimerises [39-41]. The increased solubility of recombinant $\mathrm{PAS}_{\mathrm{Bvg}}$ proteins containing large portions of the $\mathrm{C}$ - and $\mathrm{N}$-terminal flanking $\alpha$ helices argues that the latter contribute to dimer formation, as described for some other PAS domains $[42,43]$. The outer surfaces of the $\beta$ sheet of PAS cores are generally hydrophobic, and in other PAS dimers they participate in the interface or are apposed to flanking helices $[8,13,44]$. This also appears to be the case for $\mathrm{PAS}_{\mathrm{Bvg}}$. The structural model is also in good agreement with proposed mechanisms of signal transmission by other PAS domains, with the $\beta$ sheet participating in signaling $[43,45,46]$. In the $\mathrm{PAS}_{\mathrm{Bvg}}$ model the $\beta$ sheet is well positioned to relay information to the flanking C-terminal $\alpha$ helix and thus to the kinase domain.

In the current mechanistic model, BvgS is active in its basal state, and this activity requires the integrity of the periplasmic domain, since specific substitutions or insertions in the periplasmic region of BvgS abolish activity $[6,47]$. We thus propose that in its basal, non-liganded state the periplasmic domain adopts a conformation that provides a positive signal to the system. The binding of nicotinate to the VFT2 domain modifies this conformation and strongly decreases the positive-signaling capability of the protein [6]. The distinct conformational states of the periplasmic domain most likely impose distinct conformations onto the membrane segment that are propagated via long $\alpha$ helices to the $\mathrm{PAS}_{\mathrm{Bvg}}$ domain and from there to the kinase domain underneath. In this work, we found that disruption of the coupling between $\mathrm{PAS}_{\mathrm{Bvg}}$ and its upstream or downstream $\alpha$ helices abolishes BvgS activity, as do some of the PAS cavity substitutions. We therefore propose that the conformation of the periplasmic domain generates mechanical strain in BvgS, and that a major function of the PAS domain in BvgS is to maintain, and possibly to amplify, this conformational signal. The complete loss of activity of some BvgS variants generated in this study correlates with strong decreases in thermal stability of the recombinant
PAS domain. The corresponding substitutions thus cause considerably looser structures that most likely make the $\mathrm{PAS}_{\mathrm{Bvg}}$ domain unable to maintain and/or transmit the proper conformational strain to the kinase. The importance of the PAS core for stability and activity has also been shown for other PAS domains $[35,36]$.

Another observation from this and previous work is that a number of substitutions in the PAS domain do not inactivate BvgS but render it unresponsive to negative modulation by nicotinate and sulfate $[16,47,48]$. Previously reported substitutions that make BvgS unresponsive to modulation map essentially to a PAS core loop oriented towards the N-terminal flanking helix or to the $\mathrm{N}$ terminal helix itself (Figure 2). It is thus likely that they affect the connection between the PAS core and the upstream region or the stability of the PAS dimer through its $\mathrm{N}$-terminal helices. In the current work, new substitutions that impair or abolish responsiveness to modulation were also identified in the PAS cavity. The structural stabilities of the latter two $\mathrm{PAS}_{\mathrm{Bvg}}$ variant proteins appeared to be decreased to a lower extent than those of the inactive proteins. The observation that the unresponsive BvgS PAS variants remain competent to transmit positive but not negative signals suggests that transmission of modulating signals implies an increased conformational strain relative to the basal, positive-signaling state.

Our results do not support the hypothesis that $\mathrm{PAS}_{\mathrm{BvgS}}$ has a heme co-factor. Thus, the $\mathrm{His}_{643} \mathrm{Ala}$ substitution does not abolish BvgS activity, as would be expected from the loss of an $\mathrm{O}_{2}$-sensing heme for a strictly aerobic and virulent bacterium. However, this substitution abolishes the response of BvgS to negative modulation, and another substitution in the PAS cavity $\left(\mathrm{Cys}_{607} \mathrm{Ala}\right)$ also decreases BvgS sensitivity to nicotinate. These effects might be explained either by a moderate loosening of the PAS core because the small Ala side chain replaces a larger one, which disrupts the transmission of negative signals, or by a defect in binding a potential intracellular ligand required for transmission of negative signals. The double $\mathrm{Tyr}_{596} \mathrm{Ala}+\mathrm{Asn}_{631}$ Ala substitutions in the PAS cavity that abolish BvgS activity and strongly decrease the PAS thermal stability might also disable ligand binding in vivo. Binding of a cytoplamic ligand by the PAS domain would be consistent with the established link between the nutritional state of $B$. pertussis and its virulence [49] and with the observations that BvgAS regulates cytochrome expression and might perceive redox signals $[17,50]$. Thus, the $\mathrm{PAS}_{\mathrm{Bvg}}$ domain might sense intracellular molecule(s) whose abundance reflect(s) the metabolic state of the bacterium, and changes to the concentration of these components might affect signaling. Such a scenario would be compatible with the 'rheostat' behavior attributed to BvgS [3]. In any case, the effects of cavity mutations on BvgS activity lend strong 
support to our model that the conformation of the PAS core -intrinsically or by virtue of ligand binding-is critical for signaling.

\section{Conclusions}

Although substantial information has been gathered about how the cytoplasmic domains of BvgS work, the function of its PAS domain has remained unknown. In this work, we performed its characterization, which represents new information that contributes to our understanding of VFT-containing sensor-kinases. We showed that the recombinant PAS domain of the sensor-kinase BvgS dimerises, and that the $\mathrm{N}$ - and C-terminal $\alpha$ helical regions that flank the PAS core are critical for dimer stabilization. We identified specific amino acid residues in the PAS domain that are essential for BvgS activity, located in the PAS core and at the junctions between it and its flanking $\alpha$ helices. We thus propose a mechanical role for the PAS domain in BvgS, which is to maintain the conformational tension imposed by the periplasmic moiety of BvgS. The degree of tension in the protein determines the activity of the kinase, and modulation corresponds to an increased tension. Our model thus explains for the first time the phenotypes of a number of BvgS variants that harbor mild substitutions in the PAS domain and are unable to respond to negative modulation.

\section{Additional file}

Additional file 1: Table S1. Oligonucleotides used in this study.

\section{Abbreviations \\ TCS: Two-component system; PAS: Per/ARNT/Sim; VFT: Venus flytrap domain; TSA: Thermal shift assay; Tm: Melting (denaturation) temperature.}

\section{Competing interests}

The authors declare no competing interests.

\section{Authors' contributions}

$E D, J H, F J-D$ and RA designed the study; ED, JH, AW performed the experiments; ED, JH, AW, CL, FJ-D and RA wrote the paper. All authors have read and approved the final version of manuscript.

\section{Acknowledgements}

We thank Eve Willery for the construction of BPSM $\triangle$ bvgA. E. D. was supported by a pre-doctoral grant from the French Ministry for Research and then by a grant from the Fonds de la Recherche Médicale (FRM). This work was supported by funds from INSERM, CNRS, and University Lille-Nord de France.

\footnotetext{
Author details

${ }^{1}$ Institut Pasteur de Lille, Center for Infection and Immunity, Lille, France. ${ }^{2}$ CNRS UMR8204, Lille, France. ${ }^{3}$ INSERM U1019, Lille, France. ${ }^{4}$ Univ Lille Nord de France, 59019 Lille, France. ${ }^{5}$ VIB Department of Structural Biology, Free University of Brussels, Pleinlaan 2, Brussels 1050 Belgium. ${ }^{6}$ Present address: Department of Biochemistry and Molecular Biology, University of Chicago, Chicago, IL, USA.
}

Received: 17 April 2013 Accepted: 19 July 2013

Published: 24 July 2013

\section{References}

1. Gao R, Stock AM: Biological insights from structures of two-component proteins. Annu Rev Microbiol 2009, 63:133-154.

2. Casino P, Rubio V, Marina A: The mechanism of signal transduction by two-component systems. Curr Opin Struct Biol 2010, 20:763-771.

3. Cotter PA, Jones AM: Phosphorelay control of virulence gene expression in Bordetella. Trends Microbiol 2003, 11:367-373.

4. Uhl MA, Miller JF: Integration of multiple domains in a two-component sensor protein: the Bordetella pertussis BvgAS phosphorelay. EMBO J 1996, 15:1028-1036.

5. Jacob-Dubuisson F, Wintjens R, Herrou J, Dupré E, Antone R: BvgS of pathogenic Bordetellae: a paradigm for sensor kinase with Venus Flytrap perception domains. In Two-component system in bacteria. Edited by Gros R, Beier D. Norfolk, UK: Caister Academic Press; 2012:57-83.

6. Herrou J, Bompard C, Wintjens R, Dupre E, Willery E, et al: Periplasmic domain of the sensor-kinase BvgS reveals a new paradigm for the Venus flytrap mechanism. Proc Natl Acad Sci USA 2010, 107:17351-17355.

7. Taylor BL, Zhulin IB: PAS domains: internal sensors of oxygen, redox potential, and light. Microbiol Mol Biol Rev 1999, 63:479-506.

8. Möglich A, Ayers RA, Moffat K: Structure and signaling mechanism of PerARNT-Sim domains. Structure 2009, 17:1282-1294.

9. Henry JT, Crosson S: Ligand-binding PAS domains in a genomic, cellular, and structural context. Annu Rev Microbiol 2011, 65:261-286.

10. Little R, Salinas P, Slavny P, Clarke TA, Dixon R: Substitutions in the redoxsensing PAS domain of the NifL regulatory protein define an intersubunit pathway for redox signal transmission. Mol Microbiol 2011, 82:222-235.

11. Slavny P, Little R, Salinas P, Clarke TA, Dixon R: Quaternary structure changes in a second Per-Arnt-Sim domain mediate intramolecular redox signal relay in the NifL regulatory protein. Mol Microbiol 2010, 75:61-75.

12. Cheung J, Hendrickson WA: Crystal structures of C4-dicarboxylate ligand complexes with sensor domains of histidine kinases DcuS and DctB. J Biol Chem 2008, 283:30256-30265.

13. Sevvana M, Vijayan V, Zweckstetter M, Reinelt S, Madden DR, et al: A ligandinduced switch in the periplasmic domain of sensor histidine kinase CitA. J Mol Biol 2008, 377:512-523.

14. Zhang Z, Hendrickson WA: Structural characterization of the predominant family of histidine kinase sensor domains. J Mol Biol 2010, 400:335-353.

15. Pappalardo L, Janausch IG, Vijayan V, Zientz E, Junker J, et al: The NMR structure of the sensory domain of the membranous two-component fumarate sensor (histidine protein kinase) DcuS of Escherichia coli. J Biol Chem 2003, 278:39185-39188.

16. Beier D, Deppisch H, Gross R: Conserved sequence motifs in the unorthodox BvgS two-component sensor protein of Bordetella pertussis. Mol Gen Genet 1996, 252:169-176.

17. Bock A, Gross R: The unorthodox histidine kinases BvgS and EvgS are responsive to the oxidation status of a quinone electron carrier. Eur $J$ Biochem 2002, 269:3479-3484.

18. Huth JR, Bewley CA, Jackson BM, Hinnebusch AG, Clore GM, et al: Design of an expression system for detecting folded protein domains and mapping macromolecular interactions by NMR. Protein Sci 1997, 6:2359-2364.

19. Herrou J, Debrie AS, Willery E, Renaud-Mongenie G, Locht C, et al: Molecular evolution of the two-component system BvgAS involved in virulence regulation in Bordetella. PLoS One 2009, 4:e6996.

20. Antoine R, Alonso S, Raze D, Coutte L, Lesjean S, et al: New virulenceactivated and virulence-repressed genes identified by systematic gene inactivation and generation of transcriptional fusions in Bordetella pertussis. J Bacteriol 2000, 182:5902-5905.

21. Stibitz S, Black W, Falkow S: The construction of a cloning vector designed for gene replacement in Bordetella pertussis. Gene 1986, 50:133-140.

22. King-Scott J, Konarev PV, Panjikar S, Jordanova R, Svergun DI, et al: Structural characterization of the multidomain regulatory protein Rv1364c from Mycobacterium tuberculosis. Structure 2011, 19:56-69.

23. Pantoliano MW, Petrella EC, Kwasnoski JD, Lobanov VS, Myslik J, et al: Highdensity miniaturized thermal shift assays as a general strategy for drug discovery. J Biomol Screen 2001, 6:429-440.

24. Imaizumi A, Suzuki Y, Ono S, Sato Y, Sato H: Heptakis (2,6-O-dimethyl)betacyclodextrin: a novel growth stimulant for Bordetella pertussis phase I. J Clin Microbiol 1983, 17:781-786.

25. Altschul SF, Gish W, Miller W, Myers EW, Lipman DJ: Basic local alignment search tool. J Mol Biol 1990, 215(3):403-410. 
26. Sali A, Blundell TL: Comparative protein modelling by satisfaction of spatial restraints. J Mol Biol 1993, 234(3):779-815.

27. Krivov GG, Shapovalov MV MV, Dunbrack RL Jr: Improved prediction of protein side-chain conformations with SCWRL4. Proteins 2009, 77(4):778-795

28. Wiederstein M, Sippl MJ: ProSA-web: interactive web service for the recognition of errors in three-dimensional structures of proteins. Nucl Acids Res 2007, 35:W407-410. Web Server issue.

29. Hao B, Isaza C, Arndt J, Soltis M, Chan MK: Structure-based mechanism of $\mathrm{O} 2$ sensing and ligand discrimination by the FixL heme domain of Bradyrhizobium japonicum. Biochemistry 2002, 41:12952-12958.

30. Miyatake H, Mukai M, Park SY, Adachi S, Tamura K, et al: Sensory mechanism of oxygen sensor FixL from Rhizobium meliloti: crystallographic, mutagenesis and resonance Raman spectroscopic studies. J Mol Biol 2000, 301:415-431.

31. Gilles-Gonzalez MA, Gonzalez G: Signal transduction by heme-containing PAS-domain proteins. J Appl Physiol 2004, 96:774-783.

32. Melton AR, Weiss AA: Characterization of environmental regulators of Bordetella pertussis. Infect Immun 1993, 61:807-815.

33. Herrou J, Crosson S: Function, structure and mechanism of bacterial photosensory LOV proteins. Nat Rev Microbiol 2011, 9:713-723.

34. Malpica R, Franco B, Rodriguez C, Kwon O, Georgellis D: Identification of a quinone-sensitive redox switch in the ArcB sensor kinase. Proc Natl Acad SCi USA 2004, 101:13318-13323.

35. Philip AF, Kumauchi M, Hoff WD: Robustness and evolvability in the functional anatomy of a PER-ARNT-SIM (PAS) domain. Proc Natl Acad Sci USA 2010, 107:17986-17991.

36. Campbell AJ, Watts KJ, Johnson MS, Taylor BL: Gain-of-function mutations cluster in distinct regions associated with the signalling pathway in the PAS domain of the aerotaxis receptor, Aer. Mol Microbiol 2010, 77:575-586.

37. Kumauchi M, Kaledhonkar S, Philip AF, Wycoff J, Hara M, et al: A conserved helical capping hydrogen bond in PAS domains controls signaling kinetics in the superfamily prototype photoactive yellow protein. $J \mathrm{Am}$ Chem Soc 2010, 132:15820-15830.

38. Möglich A, Ayers RA, Moffat K: Design and signaling mechanism of lightregulated histidine kinases. J Mol Biol 2009, 385:1433-1444.

39. Beier D, Schwarz B, Fuchs TM, Gross R: In vivo characterization of the unorthodox BvgS two-component sensor protein of Bordetella pertussis. J Mol Biol 1995, 248:596-610.

40. Perraud AL, Kimmel B, Weiss V, Gross R: Specificity of the BvgAS and EvgAS phosphorelay is mediated by the C- terminal HPt domains of the sensor proteins. Mol Microbiol 1998, 27:875-887.

41. Perraud AL, Rippe K, Bantscheff M, Glocker M, Lucassen M, et al: Dimerization of signalling modules of the EvgAS and BvgAS phosphorelay systems. Biochim Biophys Acta 2000, 1478:341-354

42. Little R, Slavny P, Dixon R: Influence of PAS domain flanking regions on oligomerisation and redox signalling by NifL. PLoS One 2012, 7:e46651.

43. Key J, Hefti M, Purcell EB, Moffat K: Structure of the redox sensor domain of Azotobacter vinelandii NifL at atomic resolution: signaling, dimerization, and mechanism. Biochemistry 2007, 46:3614-3623.

44. Kurokawa H, Lee DS, Watanabe M, Sagami I, Mikami B, et al: A redoxcontrolled molecular switch revealed by the crystal structure of a bacterial heme PAS sensor. J Biol Chem 2004, 279:20186-20193.

45. Evans MR, Card PB, Gardner KH: ARNT PAS-B has a fragile native state structure with an alternative beta-sheet register nearby in sequence space. Proc Natl Acad Sci USA 2009, 106:2617-2622.

46. Park H, Suquet C, Satterlee JD, Kang C: Insights into signal transduction involving PAS domain oxygen-sensing heme proteins from the $\mathrm{X}$-ray crystal structure of Escherichia coli Dos heme domain (Ec DosH). Biochemistry 2004, 43:2738-2746.

47. Miller JF, Johnson SA, Black WJ, Beattie DT, Mekalanos JJ, et al: Constitutive sensory transduction mutations in the Bordetella pertussis bvgS gene. J Bacteriol 1992, 174:970-979.

48. Manetti R, Arico B, Rappuoli R, Scarlato V: Mutations in the linker region of BvgS abolish response to environmental signals for the regulation of the virulence factors in Bordetella pertussis. Gene 1994, 150:123-127.
49. Nakamura MM, Liew SY, Cummings CA, Brinig MM, Dieterich C, et al: Growth phase- and nutrient limitation-associated transcript abundance regulation in Bordetella pertussis. Infect Immun 2006, 74:5537-5548.

50. Ezzell JW, Dobrogosz WJ, Kloos WE, Manclark CR: Phase-shift markers in the genus Bordetella: loss of cytochrome d-629 in phase IV variants. Microbios 1981, 31:171-181.

doi:10.1186/1471-2180-13-172

Cite this article as: Dupré et al:: Characterization of the PAS domain in the sensor-kinase BvgS: mechanical role in signal transmission. $B M C$ Microbiology 2013 13:172.

\section{Submit your next manuscript to BioMed Central and take full advantage of:}

- Convenient online submission

- Thorough peer review

- No space constraints or color figure charges

- Immediate publication on acceptance

- Inclusion in PubMed, CAS, Scopus and Google Scholar

- Research which is freely available for redistribution

Submit your manuscript at www.biomedcentral.com/submit
() Biomed Central 